\title{
A prediction model of specific productivity index using least square support vector machine method
}

\author{
Chunxin $\mathrm{Wu}^{1 \oplus *}$, Shaopeng Wang ${ }^{1}$, Jianwei Yuan ${ }^{1}$, Chao $\mathrm{Li}^{1}$, Qi Zhang ${ }^{2}$ \\ ${ }^{1}$ Bohai Oilfield Research Institute, Tianjin Branch of CNOOC (China) Limited, Tianjin 300452, P. R. China \\ ${ }^{2}$ School of Earth Resources, China University of Geosciences, Wuhan 430074, P. R. China
}

Keywords:

Least square support vector machines productivity evaluation

specific productivity index

Huanghekou Sag

Bohai Oilfield

Cited as:

Wu, C., Wang, S., Yuan, J., Li, C., Zhang, Q. A prediction model of specific productivity index using least square support vector machine method. Advances in Geo-Energy Research, 2020, 4(4): 460-467, doi: 10.46690/ager.2020.04.10.

\begin{abstract}
:
In the design of oilfield development plans, specific productivity index plays a vital role. Especially for offshore oilfields, affected by development costs and time limits, there are shortcomings of shorter test time and fewer test sampling points. Therefore, it is very necessary to predict specific productivity index. In this study, a prediction model of the specific productivity index is established by combining the principle of least squares support vector machine (LS-SVM) with the calculation method of the specific productivity index. The model uses logging parameters, crude oil experimental parameters and the specific productivity index of a large number of test well samples as input and output items respectively, and finally predicts the specific productivity index of non-test wells. It reduces the errors caused by short training time, randomness of training results and insufficient learning. A large number of sample data from the Huanghekou Sag in Bohai Oilfield were used to verify the prediction model. Comparing the specific productivity index prediction results of LS-SVM and artificial neural networks (ANNs) with actual well data respectively, the LS-SVM model has a better fitting effect, with an error of only $3.2 \%$, which is $12.1 \%$ lower than ANNs. This study can better reflect the impact of different factors on specific productivity index, and it has important guiding significance for the evaluation of offshore oilfield productivity.
\end{abstract}

\section{Introduction}

Oil well productivity is a comprehensive index reflecting the dynamic characteristics of oil reservoirs, which plays an important role in reservoir engineering research. It not only determines the scale of oilfield development investment, but also determines whether the oilfield has economic benefits (AlRbeawi, 2018; Li et al., 2018; Wang, 2018). Due to the huge development investment of offshore oilfields, evaluation results of too high or too low production capacity will cause major losses in the development process. In recent years, there has been a big difference between the overall development plan forecasted production capacity and actual production data of the Bohai New Oilfield. Especially in the situation of low oil prices, the accuracy of productivity assessment is crucial (Xie et al., 1997; Zhang et al., 2002; Tang et al., 2009; Chen and Zheng, 2012; Wang et al., 2015, 2016). In order to reduce development risks and production costs, research on productivity of offshore oil wells is of practical significance.

At present, there are two methods for predicting specific production indexes: Drill-stem testing (DST) test and formula calculation method. Unlike onshore oilfields, offshore oilfield development is limited by cost, which has a series of problems. First, there are few exploration wells and samples because of the high development cost (Luo et al., 2011). Secondly, DST is usually not implemented due to the constraints of climate, project time and location. Stalgorova et al. (Stalgorova, 2012; Torcuk et al., 2013; Stalgorova and Mattar, 2013; Zhu et al., 2014; Wang et al., 2015; Yuan et al., 2017) used mirror reflection method, point source function and Laplace transform to establish steady-state and non-steady state productivity formulas. Boyrdet (1985) established a multi-layer reservoir, and used pressure derivatives and pressure curves to calculate skin effects and wellbore storage. However, the model did not consider the impact of multi-layer combined mining on productivity. Rinaldi (1997) calculated the relationship between

\section{Yandy
Scientific}

Press
${ }^{*}$ Corresponding author.

E-mail address: wuchx2@cnooc.com.cn (C.Wu); wangshp4@cnooc.com.cn (S.Wang); yuanjw4@cnooc.com.cn (J. Yuan);

lichao2@cnooc.com.cn (C. Li); qizhang@cug.edu.cn (Q. Zhang).

2207-9963 (C) The Author(s) 2020.

Received November 30, 2020; revised December 14, 2020; accepted December 14, 2020; available online December 16, 2020. 
the productivity index and the corrected relative permeability curve based on the density, porosity, shale content, and relative permeability of the reservoir, and predicted the productivity of the reservoir. According to the theoretical basis that there is a proportional relationship between specific productivity index and mobility, mobility can be used as the main factor affecting reservoir productivity. Cheng (1999) used the formation resistivity and flushing resistivity to evaluate and predict oil and gas reservoir productivity. Zhang et al. (2015) established the non-steady state productivity formula under different boundary conditions to obtain the dimensionless oil production index curve and analyzed the correction coefficients of different fault distances and fault angles. Zhang et al. (2014) used reservoir engineering methods, equivalent seepage theory and conformal transformation principles to establish pseudo-steady state horizontal well productivity. The parameters for calculating the specific productivity index by formula include reservoir effective thickness, oil viscosity, oil volume coefficient, pressure difference, formation oil supply radius, radius, skin factor, and formation effective permeability. Among these parameters, the reservoir supply radius, pressure difference, skin factor and other parameters can only be obtained through dynamic test data, which cannot be accurately predicted.

From the theoretical research of productivity index and the actual application of domestic and foreign research, we know that the productivity calculation is mainly based on Darcy's law (Liu et al., 2019). The solution process of permeability in Darcy's formula is mainly divided into two steps. Firstly, the porosity is obtained according to the interpretation of the neutron curve, and then the permeability is calculated according to the relationship between the porosity and the permeability obtained from the core experiment. However, there are some errors in this solution process. The regression relationship between porosity and permeability obtained in the experiment cannot reflect the real situation of the formation, and the regression accuracy is low. Therefore, based on the seepage theory, this paper has determined the main factors affecting productivity, and choose the area with a higher degree of exploration in the Huanghekou Sag of Bohai Oilfield as the research object. Using LS-SVM for training on logging data and PVT data in this area, a productivity index prediction model was obtained. And this paper putted forward the prediction method of specific productivity index, which has important guiding significance for the evaluation of offshore oil field productivity.

\section{Research method}

LS-SVM is a machine learning model based on statistical theory, which can effectively process small sample data and nonlinear data sets, thereby avoiding the problem of local optimization in the model optimization process. Therefore, it is widely used in parameter modeling in various fields. Wei et al. (2008) proposed a nonlinear multi-sensor signal reconstruction method based on LS-SVM, and believed that the regression function constructed by LS-SVM has good approximate performance for the inverse function of nonlinear multi-sensor. This function can achieve high-precision, high- stability reconstruction and reconstruction under different nonlinear conditions, and has better generalization performance. Zhou et al. (2009) established an intelligent prediction model for LS-SVM recovery rate, and extracted the color and size characteristics of the foam through the foam image processing method, which effectively solved the problem of incomplete information in the prediction algorithm. Suykens et al. (2002) proposed a predictive model that combines rough set theory and LS-SVM method, which better solves the redundant index and nonlinear forecasting problems in the forecast of economic prosperity index. In order to quantitatively describe the large pore channel and consider the dynamic and static response characteristics, Chen et al. (2015) proposed a method to predict the large channel using the LS-SVM model.

LS-SVM is one of the most important data mining and machine learning methods (Xu et al., 2007; Bai et al., 2010; Zhong et al., 2011; Yuan et al., 2017). It evolved from the well-known SVM learning algorithm and has advantages in scalable data learning speed. Compared with the artificial neural networks (ANNs) method (Dong et al., 2019), it has great advantages in solving practical problems such as small samples, nonlinearity, high dimensionality and local minimum points, so it has been widely used in many fields. The overall idea of the method is: the input space is transformed into a high-dimensional feature space through nonlinear transformation, and the inseparable data in the original input space becomes linearly separable, so as to obtain the optimal hyperplane in the feature space. The nonlinear transformation used in this process can be realized by defining an appropriate Kernel function. Therefore, the nonlinear regression of the low-dimensional input space is transformed into a highdimensional linear regression problem, while avoiding the complex algorithm of the midpoint in the high-dimensional space.

Set the sample to $S=\left\{\left(x_{i}, y_{i}\right)\right\}(i=1,2, \ldots, N)$, where $x_{i}$ is input parameter, $y_{i}$ is output parameter, $N$ is number of sample. In order to describe hyper plane, margin of error $\varepsilon_{i}$ is introduced, the constrain condition is:

$$
y_{i}\left[\omega^{T} \phi\left(x_{i}\right)+b\right]-1+\varepsilon_{i}=0
$$

In equation: $\phi\left(x_{i}\right)$ is the mapping of input parameter in a higher dimensional space; $\omega$ is the normal direction of the hyper plane; $b$ is a constant. For getting the optimal separating hyper plane, let the minimum distance between the training sets and the hyper plane maximize. For the method of LSSVM, the model is quadratic programming problem.

$$
\operatorname{Min} \frac{1}{2} \omega^{T} \omega+C \sum_{i=1}^{N} \varepsilon_{i}^{2}=0
$$

where $C$ is penalty factor.

To solve these problems, Lagrange function is introduced as follows.

$$
\begin{aligned}
L(\omega, \varepsilon, b, a)= & \frac{1}{2}\|\omega\|^{2}+\frac{1}{2} C \sum_{i=1}^{N} \varepsilon_{i}^{2} \\
& +\sum_{i=1}^{N} \alpha_{i}\left\{y_{i}\left[\omega^{T} \phi\left(x_{i}\right)+b\right]-1+\varepsilon_{i}\right\}
\end{aligned}
$$


where $\alpha$ is the factor of Lagrange function.

The optimization conditions are as follows.

$$
\left\{\begin{array}{l}
\frac{\partial L}{\partial \omega}=0 \\
\frac{\partial L}{\partial b}=0 \\
\frac{\partial L}{\partial \varepsilon}=0 \\
\frac{\partial L}{\partial \alpha}=0
\end{array}\right.
$$

Then:

$$
\left\{\begin{array}{l}
\omega-\sum_{i=1}^{N} \alpha_{i} y_{i} \phi\left(x_{i}\right)=0 \\
\sum_{i=1}^{N} \alpha_{i} y_{i}=0 \\
\alpha_{i}=C \varepsilon_{i} \\
y_{i}\left[\omega^{T} \phi\left(x_{i}\right)+b\right]-1+\varepsilon_{i}=0
\end{array}\right.
$$

To solve the Eq. (5), the LS-SVM model is introduced.

$$
y_{i}=\sum_{i=1}^{N} \alpha_{i} \kappa_{i}\left(x, x_{i}\right)+b
$$

where $\kappa_{i}\left(x, x_{i}\right)$ is Kernel function. This equation can be used for categories identification, performance evaluation and prediction parameters.

\section{Establishment of prediction model}

\subsection{The determination of input parameters}

According to Darcy's law, the specific productivity index expression of oil well is as follows.

$$
J_{o}=\frac{0.543 K K_{r o}}{\mu_{o}\left(\operatorname{Ln} \frac{R_{e}}{R_{w}}+s\right)}
$$

where $J_{o}$ is the specific productivity index, $\mathrm{m}^{3} /(\mathrm{d} \cdot \mathrm{MPa} \cdot \mathrm{m}) ; K$ is permeability, $\mathrm{mD} ; K_{r o}$ is the relative permeability of oil phase, fraction; $\mu_{o}$ is the viscosity of crude, $\mathrm{mPa} \cdot \mathrm{s}, R_{e}$ is the supply radius, $\mathrm{m} ; R_{w}$ is the wellbore radius, $\mathrm{m} ; s$ is the skin factor, fraction.

The Eq. (7) shown that the specific productivity index is mainly affected by reservoir permeability, relative permeability of oil phase, crude oil viscosity and supply radius. Skin factor is obtained through well test interpretation.

$$
A=\frac{0.543}{\left(\operatorname{Ln} \frac{R_{e}}{R_{w}}+s\right)}
$$

For a certain oilfield, $A$ is the constant, then the Eq. (7) can be simplified as:

$$
J_{o}=\frac{A K K_{r o}}{\mu_{o}}
$$

According to the Eq. (9), there is linear relationship between specific productivity index and mobility. However, the

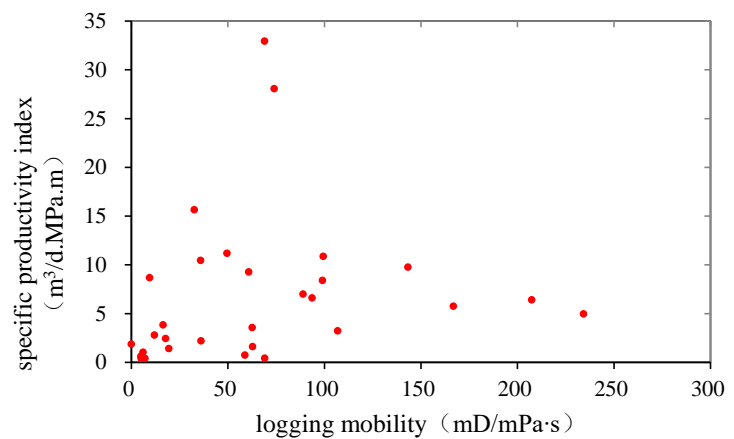

Fig. 1. The relationship between the logging mobility and specific productivity index.

actual data did not show an obvious linear relationship (Fig. 1). The main reason is that there is no better correspondence between logging permeability and oil well productivity.

According to Eq. (9), the influencing factors of production index are reservoir permeability, relative permeability and crude oil viscosity. Among these parameters, crude oil viscosity can be obtained through crude oil experiments, while the remaining parameters can be obtained through logging interpretation data.

\section{1) Characterization of permeability}

The solution process of permeability is mainly divided into two steps. Firstly, the porosity is obtained according to the interpretation of the neutron curve, and then the permeability is calculated according to the relationship between the porosity and the permeability obtained from the core experiment. However, this method is greatly affected by the accuracy of linear regression. Generally, the porosity and permeability only represent the characteristics of rock pore structure, and the relationship between porosity and permeability is not sufficient to reflect the complexity of the reservoir. A large number of experiments have shown that as the mud content in the formation increases, the blocking effect of the flow channel is enhanced, which leads to a decrease in permeability. Therefore, this paper predicts the permeability through the multiple relationship between mud content and porosity. In this paper, by analyzing grain size data and rock physical properties of the Huanghekou Sag, the relationship between permeability, porosity and mud content is obtained by regression, and thus the permeability prediction formula is proposed.

$$
K=c\left(\frac{\phi}{V_{s h}}\right)^{d}
$$

where $\phi$ is porosity, fraction; $V_{s h}$ is mud content, fraction; $c, d$ are experience factor, fraction.

\section{2) Characterization of effective permeability}

Many scholars have conducted research on effective permeability, and the common expression is as follows.

$$
K_{r o}=e S_{w}^{f}
$$

According to Archie's formula in logging

$$
S_{w}=\left(\frac{a b R_{w}}{R_{t} \phi^{m}}\right)^{\frac{1}{n}}
$$




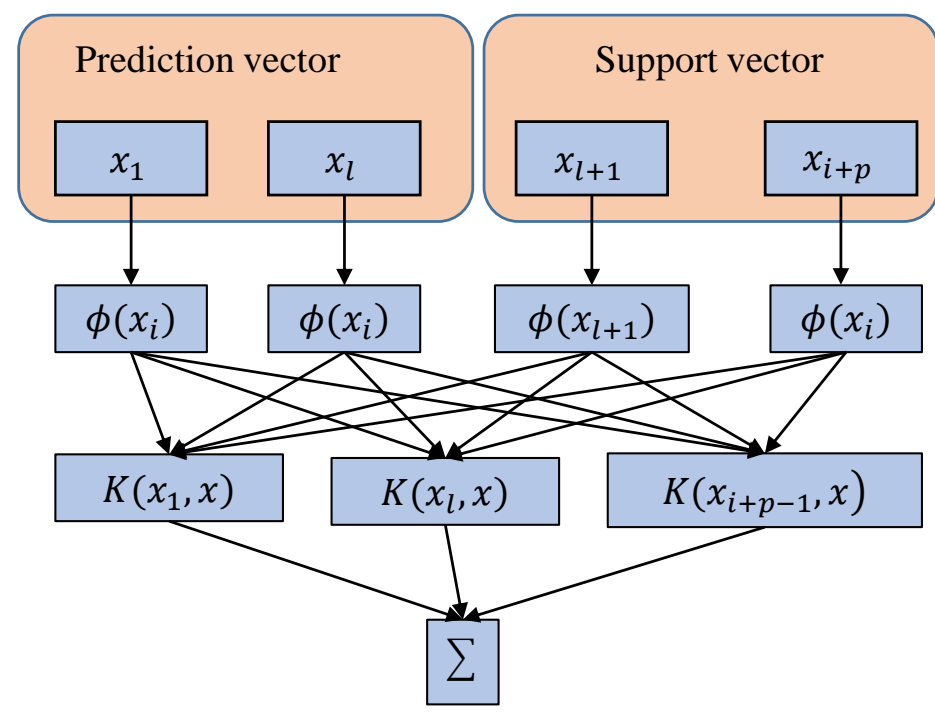

Nonlinear function

Kernel function

Prediction results

Fig. 2. The prediction process of LS-SVM.

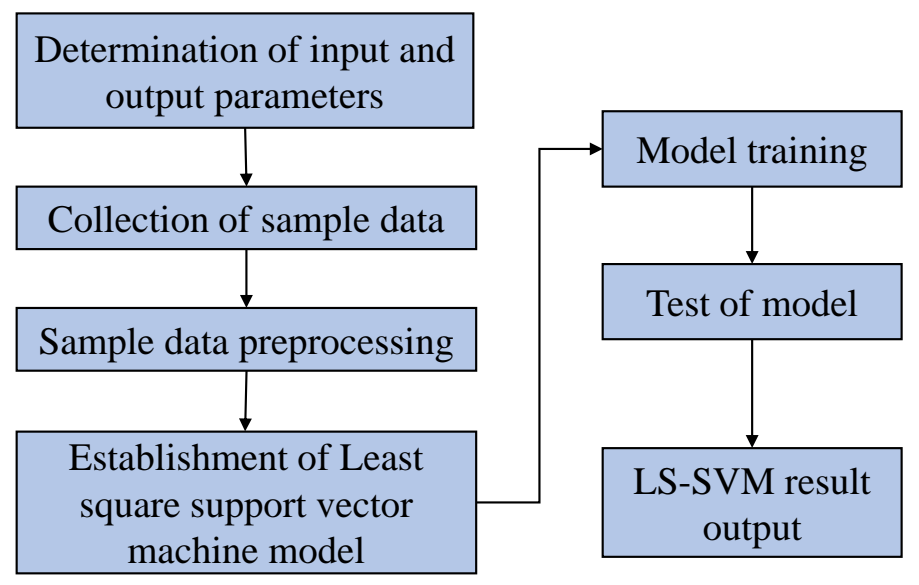

Fig. 3. Solution flow chart.

where $R_{w}$ is electrical resistivity of formation water, $\Omega \cdot \mathrm{m}$; $R_{t}$ is electrical resistivity of formation, fraction; $S_{w}$ is water saturation, $\% ; a, b, e, f, m, n$ are experience factor, fraction.

Then

$$
K_{r o}=\frac{e\left(a b R_{w}\right)^{\frac{f}{n}}}{R_{t}^{\frac{f}{n}} \phi^{\frac{m f}{n}}}
$$

In summary, this paper will predict the specific productivity index through the four parameters of resistivity, porosity, shale content and formation crude oil viscosity.

\subsection{Prediction model construction idea and calculation process}

On the basis of determining the influence parameters of a specific productivity index, the sample data is input to LSSVM. The input vector is mapped to the high dimensional feature space by the nonlinear transformation. Then the optimal decision function is constructed by using the structural risk minimization principle, and the point product transport in the high dimensional feature space is subtly replaced by the kernel number of the original space. The influence index space is mapped to the high dimensional feature space, and then the linear regression is carried out in the output space, and the performance of the system is continuously improved by using historical data or experience, so as to achieve the role of intelligent analysis and prediction data. LS-SVM is composed of input layer, feature layer and output layer. LSSVM prediction process can be regarded as the process of regression algorithm. The basic process is shown in Fig. 2 .

The basic idea of predicting specific productivity index through LS-SVM is shown in Fig. 3.

\section{Field examples}

\subsection{Research area and data sources}

Huanghekou Sag is located in the southeast of Bohai Bay Basin, with an area of $3,800 \mathrm{~km}^{2}$. It is $180 \mathrm{~km}$ away from 
Table 1. The sample point data of the training set.

\begin{tabular}{|c|c|c|c|c|c|c|c|c|}
\hline Oilfield & Well & Layer & Test order & $\begin{array}{l}\text { Resistance } \\
\Omega \cdot \mathrm{m}\end{array}$ & $\begin{array}{l}\text { Porosity } \\
\%\end{array}$ & $\begin{array}{l}\text { Mud content } \\
\%\end{array}$ & $\begin{array}{l}\text { Formation crude viscosity } \\
\mathrm{mPa} \cdot \mathrm{s}\end{array}$ & $\begin{array}{l}\text { Specific productivity index } \\
\mathrm{m}^{3} /(\mathrm{MPa} \cdot \mathrm{d} \cdot \mathrm{m})\end{array}$ \\
\hline \multirow{6}{*}{ BH1 } & \multirow[b]{2}{*}{ BH1-1 } & \multirow{2}{*}{$E_{3} d^{3}$} & DST1 & 19.5 & 19.0 & 12.2 & 7.54 & 1.8 \\
\hline & & & DST2 & 14.9 & 21.2 & 11.1 & 7.54 & $\begin{array}{l}1.0 \\
2.0\end{array}$ \\
\hline & \multirow{2}{*}{ BH1-2 } & $E_{3} d^{3}$ & DST2 & 9.1 & 20.5 & 11.8 & 11.28 & 0.7 \\
\hline & & $\mathrm{E}_{3} \mathrm{~s}^{2}$ & DST1 & 8.6 & 18.4 & 10.7 & 1.36 & 4.3 \\
\hline & BH1-3 & $E_{3} d^{3}$ & DST2 & 7.6 & 17.7 & 12.0 & 11.28 & 0.7 \\
\hline & BH1-4 & $\mathrm{E}_{3} \mathrm{~s}^{2}$ & DST1 & 6.8 & 17.2 & 9.6 & 1.36 & 3.7 \\
\hline \multirow{4}{*}{$\mathrm{BH} 2$} & & \multirow{4}{*}{$\mathrm{N}_{1} \mathrm{~m}^{L}$} & DST1 & 4.3 & 24.2 & 24.9 & 8.53 & 0.4 \\
\hline & BH2-1 & & DST2 & 12.9 & 32.1 & 8.9 & 16.11 & 5.1 \\
\hline & BH2-2 & & DST1 & 5.3 & 18.9 & 25.4 & 8.53 & 0.3 \\
\hline & $\mathrm{BH} 2-3$ & & DST2 & 14.5 & 24.2 & 9.0 & 16.11 & 4.7 \\
\hline \multirow{4}{*}{ BH3 } & BH3-2 & \multirow{4}{*}{$E_{3} d^{3}$} & DST1 & 18.0 & 18.0 & 7.1 & 1.42 & 9.2 \\
\hline & $\mathrm{BH} 3-3$ & & DST1 & 9.1 & 32.4 & 11.2 & 4.22 & 10.2 \\
\hline & BH3-4 & & DST1 & 17.2 & 17.8 & 6.5 & 1.46 & 10.6 \\
\hline & BH3-5 & & DST1 & 9.4 & 33.5 & 9.9 & 4.67 & 9.8 \\
\hline \multirow{12}{*}{ BH4 } & \multirow{4}{*}{$\begin{array}{l}\text { BH4-1 } \\
\text { BH4-2 }\end{array}$} & \multirow{4}{*}{$\mathrm{N}_{1} \mathrm{~m}^{L}$} & DST1 & 8.2 & 31.0 & 7.4 & 5.40 & 8.20 \\
\hline & & & DST2 & 13.2 & 33.0 & 4.3 & 12.50 & 12.80 \\
\hline & & & DST1 & 14.7 & 23.5 & 10.7 & 1.32 & 15.83 \\
\hline & & & DST2 & 6.5 & 27.3 & 9.9 & 4.94 & 5.24 \\
\hline & \multirow{2}{*}{ BH4-5 } & \multirow{3}{*}{$\mathrm{Ng}$} & DST1 & 7.3 & 21.0 & 10.6 & 1.25 & 6.2 \\
\hline & & & DST1a & 7.3 & 21.0 & 10.6 & 1.25 & 5.5 \\
\hline & \multirow{2}{*}{ BH4-6 } & & DST1 & 9.1 & 40.6 & 7.3 & 5.63 & 9.44 \\
\hline & & & DST2 & 15.3 & 39.7 & 3.7 & 14.69 & 12.89 \\
\hline & $\mathrm{BH}_{4} 7$ & $\mathrm{~N}_{1} \mathrm{~m}^{\mathrm{L}}$ & DST1 & 16.9 & 26.6 & 9.1 & 1.11 & 19.21 \\
\hline & & & DST2 & 7.0 & 28.8 & 9.2 & 5.63 & 5.43 \\
\hline & & & DST1 & 8.4 & 23.7 & 8.4 & 1.29 & 5.9 \\
\hline & BH4-8 & $\mathrm{Ng}$ & DST1a & 9.1 & 21.6 & 9.4 & 1.10 & 6.4 \\
\hline & BH5-3 & $\mathrm{N}_{1} \mathrm{~m}^{L}$ & DST1 & 17.0 & 34.0 & 7.7 & 20.4 & 8.4 \\
\hline RH5 & BH5-4 & $\mathrm{Ng}$ & DST1 & 7.9 & 25.4 & 5.1 & 1.18 & 30.3 \\
\hline ВН5 & BH5-5 & $\mathrm{N}_{1} \mathrm{~m}^{L}$ & DST1 & 13.8 & 35.1 & 8.0 & 22.08 & 9.7 \\
\hline & BH5-6 & $\mathrm{Ng}$ & DST1 & 6.3 & 25.8 & 4.9 & 1.27 & 29.1 \\
\hline & & $\mathrm{F} 3 M$ & DST1 & 13.9 & 15.3 & 17.1 & 2.42 & 0.7 \\
\hline & BH6-1 & $\mathrm{E}_{2} \mathrm{~s}^{\mathrm{Sin}}$ & DST2 & 11.5 & 16.6 & 15.8 & 2.69 & 1.1 \\
\hline & & $\mathrm{N}_{1} \mathrm{~g}$ & DST3 & 6.6 & 28.3 & 6.0 & 164.00 & 0.8 \\
\hline & BH6-2 & $\mathrm{E}_{2} \mathrm{~s}^{3 M}$ & DST1 & 9.4 & 16.4 & 13.8 & 1.79 & 0.4 \\
\hline & ВН6-2 & $\mathrm{E}_{2} \mathrm{~s}^{3 U}$ & DST2 & 30.4 & 22.3 & 10.0 & 20.23 & 4.5 \\
\hline & BH6 4 & $\mathrm{~N}_{1} \mathrm{~m}^{L}$ & DST2 & 5.6 & 25.6 & 18.1 & 57.20 & 1.7 \\
\hline BH6 & ВН6-4 & $\mathrm{E}_{2} \mathrm{~s}^{3 M}$ & DST1 & 10.3 & 18.6 & 9.5 & 2.25 & 2.3 \\
\hline & BH6-9 & $\mathrm{N}_{1} \mathrm{~m}^{L}$ & DST1 & 14.8 & 26.5 & 11.2 & 178.00 & 3.0 \\
\hline & ВН6-9 & $\mathrm{N}_{1} \mathrm{~m}^{L}$ & DST2 & 9.7 & 31.0 & 6.9 & 178.00 & 1.4 \\
\hline & & & DST1 & 16.3 & 15.5 & 16.0 & 2.54 & 0.8 \\
\hline & BH6-10 & $\mathrm{E}_{2} \mathrm{~s}^{3 M}$ & DST2 & 12.9 & 17.0 & 13.9 & 2.49 & 1.4 \\
\hline & & $\mathrm{N}_{1} \mathrm{~g}$ & DST3 & 7.9 & 29.2 & 6.1 & 165.31 & 1.1 \\
\hline & BH6-12 & $\mathrm{E}_{2} \mathrm{~s}^{3 M}$ & DST1 & 11.7 & 15.2 & 13.8 & 1.55 & 0.5 \\
\hline & BH6-12 & $\mathrm{E}_{2} \mathrm{~s}^{3 U}$ & DST2 & 33.3 & 22.6 & 7.4 & 23.14 & 5.8 \\
\hline & & & DST1 & 6.1 & 27.6 & 14.0 & 1.33 & 11.9 \\
\hline & BH7-1 & & DST2 & 6.9 & 22.1 & 28.2 & 3.64 & 3.5 \\
\hline & PH7 2 & & DST1 & 5.1 & 22.9 & 17.5 & 1.18 & 3.2 \\
\hline & ВН7-2 & & DST2 & 6.0 & 23.2 & 21.4 & 3.49 & 2.8 \\
\hline BH7 & $\mathrm{BH}_{73} 3$ & $\mathrm{~N}_{1} \mathrm{~m}^{L}$ & DST1 & 5.9 & 20.3 & 22.4 & 0.40 & 6.6 \\
\hline & BH7-3 & & DST3 & 10.1 & 27.7 & 13.4 & 2.82 & 10.9 \\
\hline & BH7-4 & & DST2 & 6.1 & 20.9 & 23.3 & 3.49 & 3.4 \\
\hline & $\mathrm{PH} 75$ & & DST1 & 6.0 & 18.3 & 24.3 & 0.40 & 7.9 \\
\hline & ВН7-5 & & DST3 & 10.3 & 24.9 & 14.6 & 2.82 & 13.0 \\
\hline $\mathrm{BH}$ & BH8-1 & $\mathrm{N}_{1} \mathrm{~m}^{L}$ & DST2 & 20.5 & 33.8 & 5.5 & 11.74 & 18.5 \\
\hline ВН8 & BH8-2 & $\mathrm{N}_{1} \mathrm{~m}^{L}$ & DST2 & 20.5 & 39.1 & 6.0 & 11.74 & 19.9 \\
\hline BH9 & BH9-4 & $\mathrm{E}_{3} \mathrm{~d}^{2 L}$ & DST1 & 58.6 & 24.8 & 4.8 & 2.66 & 80.4 \\
\hline & & & DST1 & 6.4 & 21.8 & 10.8 & 1.29 & 4.4 \\
\hline ВН10 & ВН10-5 & $\mathrm{Ng}$ & DST1a & 6.9 & 19.8 & 12.2 & 1.10 & 4.7 \\
\hline & BH11-3 & $\mathrm{N}_{1} \mathrm{~m}^{L}$ & DST1 & 13.8 & 42.4 & 8.0 & 22.08 & 7.2 \\
\hline BH11 & BH11-4 & $\mathrm{Ng}$ & DST1 & 6.3 & 31.1 & 4.9 & 1.27 & 21.6 \\
\hline
\end{tabular}


Tanggu District of Tianjin in the northwest and $80 \mathrm{~km}$ away from Longkou City of Shandong Province in the southeast. The eastern and northern parts of the research area are the Miaoxi Sag and Bonan Uplift, while the southern part is connected to the Kendong Qingtuozi Uplift and the Laibei Uplift. Huanghekou Sag's overall structure, due to the action of the Western Branch of the Tan Lu strike slip fault, forms a series of East-West and northeast trending secondary faults, and forms stage zones and fault uplift zones. The central uplift zone in the center of the depression divides it into two parts: the shallower east depression and the deeper west depression. Currently, 11 oil fields in the area are under development.

The Huanghekou Sag in Bohai Oilfield has a high degree of exploration and rich exploration well data (Qian et al., 2019). Vertically, the oil layers mainly exist in the Minghuazhen Formation, Guantao Formation, Dongying Formation and Shahejie Formation. Therefore, this paper collected 63 test data and logging data from 11 oil fields in the area (Table 1). At these sample points, 60 sample points are randomly selected as the training set, and the remaining 3 sample points are used as the test set. The range of training set resistivity is 4.3-58.6 $\Omega \cdot \mathrm{m}$. The porosity ranges from $15.2 \%$ to $42.4 \%$, and shale content ranges from $3.7 \%$ to $28.2 \%$, and formation crude oil viscosity ranges from 0.4 to $178 \mathrm{mPa}$.s. The relationship between resistivity, porosity, shale content, formation crude oil viscosity and specific productivity index of training sets are shown in Figs. 4-7.

\subsection{The normalization processing of influencing factors}

In order to eliminate the different dimension influence of the support vector machine on the prediction performance, Eq. (14) is used for normalization, all the data is normalized to an interval of $[0,1]$.

$$
\overline{X_{i}}=\frac{X_{i}-X_{\min }}{X_{\max }-X_{\min }}
$$

where $\overline{X_{i}}$ is normalized data, fraction; $X_{\max }$ and $X_{\min }$ and are the maximum and minimum values in the column data respectively.

\subsection{Results analysis}

In order to verify the rationality of the model, the specific productivity index of the $\mathrm{X}$ oilfield in the Huanghekou Sag, Bohai is predicted. The oil-bearing layer of this oilfield is located in the Shahejie Formation, and its reservoir has the characteristics of high porosity and high permeability. The average porosity and average permeability of the core analysis are $29.1 \%$ and $658.2 \mathrm{mD}$, respectively. The characteristics of formation crude oil are low viscosity, low gas-oil ratio and high saturation pressure, so it is conventional crude oil, and its formation viscosity ranges from 4.86 to $5.92 \mathrm{mPa} \cdot \mathrm{s}$. The oil field only conducted two tests during the exploration and evaluation stage, and at the same time, the correlation between the mobility obtained by logging data and the specific productivity index was poor. Therefore, the prediction model

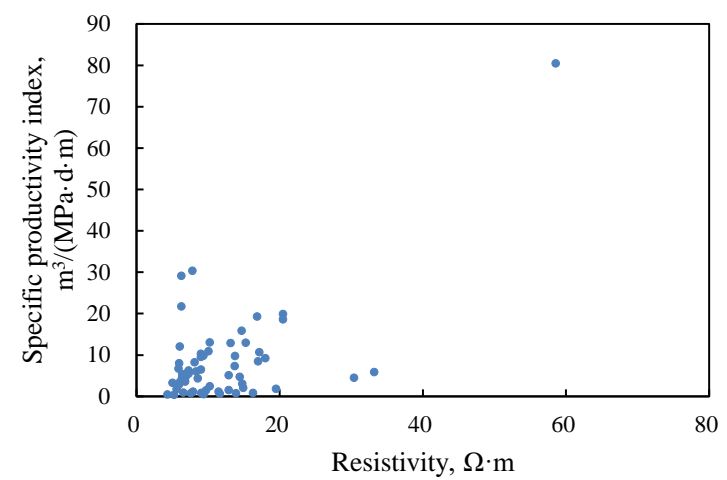

Fig. 4. The relationship between resistivity and specific productivity index of training sets.

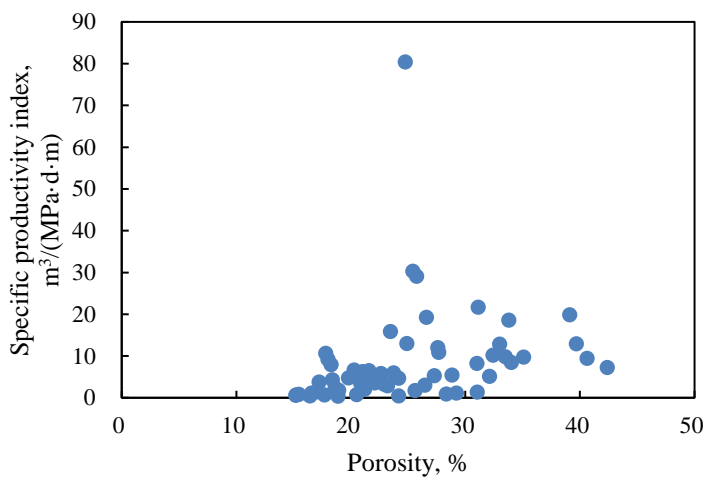

Fig. 5. The relationship between porosity and specific productivity index of training sets.

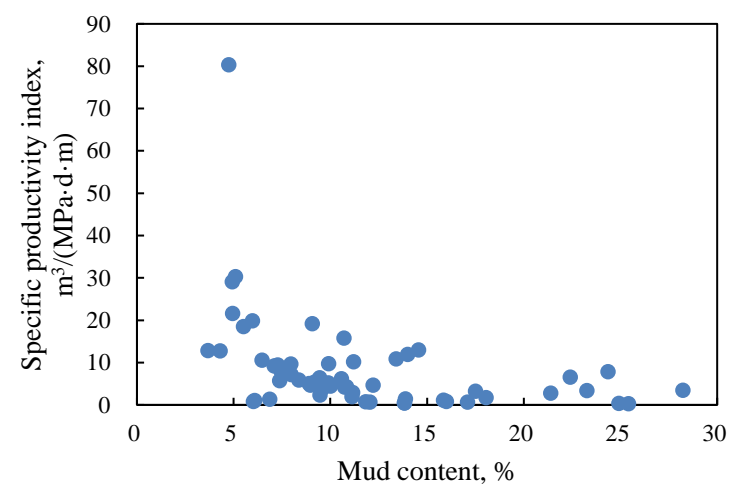

Fig. 6. The relationship between mud content and specific productivity index of training sets.

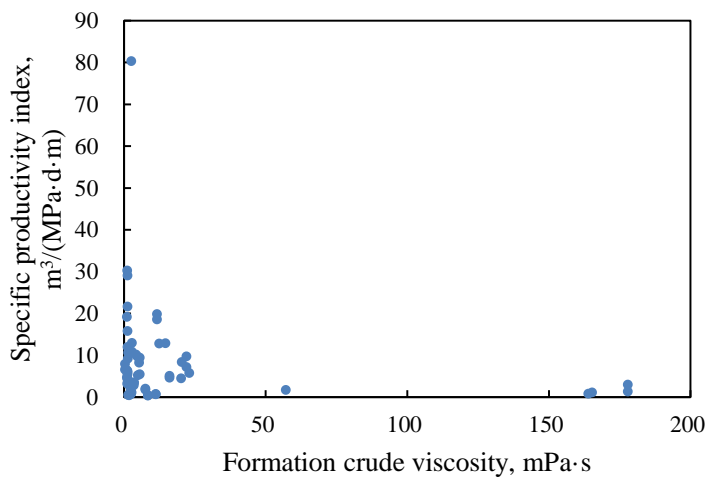

Fig. 7. The relationship between formation crude viscosity and specific productivity index of training sets. 
Table 2. Develop well productivity analysis of X oilfield in Bohai.

\begin{tabular}{|c|c|c|c|c|c|c|c|c|c|c|}
\hline \multirow[t]{2}{*}{ Well } & \multirow{2}{*}{$\begin{array}{l}\text { Resistance } \\
\Omega \cdot \mathrm{m}\end{array}$} & \multirow{2}{*}{$\begin{array}{l}\text { Permeability } \\
\mathrm{mD}\end{array}$} & \multirow{2}{*}{$\begin{array}{l}\text { Porosity } \\
\%\end{array}$} & \multirow{2}{*}{$\begin{array}{l}\text { Mud content } \\
\%\end{array}$} & \multirow{2}{*}{$\begin{array}{l}\text { Formation Viscosity } \\
\mathrm{mPa} \cdot \mathrm{s}\end{array}$} & \multicolumn{3}{|c|}{$\begin{array}{l}\text { Specific productivity index } \\
\mathrm{m}^{3} /(\mathrm{MPa} \cdot \mathrm{d} \cdot \mathrm{m})\end{array}$} & \multicolumn{2}{|c|}{ Error \% } \\
\hline & & & & & & test & LS-SVM & ANNs & LS-SVM & ANNs \\
\hline $\mathrm{A} 1$ & 3.75 & 921.5 & 29.4 & 15.02 & 5.39 & 3.9 & 3.8 & 3.5 & -2.6 & -10.3 \\
\hline A2 & 4.43 & 413.5 & 26.25 & 14.59 & 5.39 & 2.8 & 2.7 & 2.2 & -3.6 & -21.4 \\
\hline A3 & 5.12 & 652.5 & 27.51 & 14.45 & 5.39 & 2.8 & 2.9 & 3.2 & 3.6 & 14.3 \\
\hline
\end{tabular}

of this paper is applied to this oil field. According to Table 2 , the predicted value of the model is closer to the test value, and the error is within the allowable range. Comparing the specific productivity index prediction results of LS-SVM and ANNs with actual well data respectively, the LS-SVM model has a better fitting effect, with an error of only $3.2 \%$, which is $12.1 \%$ lower than ANNs. Through the comparison of different prediction methods, the reliability of LS-SVM method is further explained. Therefore, LS-SVM method can be further applied to the prediction of the specific productivity index of offshore oilfields, providing a theoretical basis and foundation for the adjustment of offshore oil reservoirs.

\section{Conclusion}

1) Offshore oil field is limited by space, construction period, weather, and development costs, and there are few exploration wells and test samples. Therefore, it is necessary to establish specific productivity index prediction model based on regional data.

2) In this paper, by considering the influencing factors of productivity index, the LS-SVM method is used to establish a quantitative prediction model of specific productivity index in the Bohai Oilfield. This model reduces the computational complexity and solves the problem of small samples.

3) Applying the LS-SVM model to the specific productivity index prediction of actual wells, the results show that the prediction results of the LS-SVM model are closer to the actual data than the ANNs model. Thus, this study can better reflect the impact of different factors on specific productivity index, and it has important guiding significance for the evaluation of offshore oilfield productivity.

\section{Acknowledgement}

The foregoing represents the perspectives of the authors of this editorial, alone. The sterling work of the conference Program and Organization committees is thankfully acknowledged. Thanks also goes to the participating scholars who actively participated, studied presentations, left comments and questions and attended all in-person sessions. It was a remarkable and rich academic feast.

\section{Conflict of interest}

The authors declare no competing interest.
Open Access This article, published at Ausasia Science and Technology Press on behalf of the Division of Porous Flow, Hubei Province Society of Rock Mechanics and Engineering, is distributed under the terms and conditions of the Creative Commons Attribution (CC BY-NC-ND) license, which permits unrestricted use, distribution, and reproduction in any medium, provided the original work is properly cited.

\section{References}

Al-Rbeawi, S. The optimal reservoir configuration for maximum productivity index of gas reservoirs depleted by horizontal wells under Darcy and non-Darcy flow conditions. J. Nat. Gas Sci. Eng. 2018, 49: 179-193.

Bai, X., Jiang, H., Wang, S., et al. Multi-step forecasting model of dynamic index for oilfield development. Fault Block Oil and Gas Field 2010, 17(3): 345-347. (in Chinese)

Boyrdet, D. Pressure behavior of layered reserviors with crossflow. Paper SPE 13628 Presented at the SPE California Regional Meeting, Bakersfield, California, 2729 March, 1985.

Chen, C., Wang, Z., Niu, W., et al. Quantitative calculation method of thief zone based on least square support vector machine. Fault Block Oil and Gas Field 2015, 22(1): 7477. (in Chinese)

Chen, Z., Zheng, Y. Productivity evaluation and optimization of exploitation methods of $\mathrm{S}$ reservoir. Journal of Southwest Petroleum University 2012, 34(2): 111-118. (in Chinese)

Cheng, M.L., Leal, M.A., Mcnaughton, D. Productivity prediction from well logs in variable grain size reservoirs cretaceous Qishn formation, republic of Yemen. Log Anal. 1999, 40(1): 34-32.

Dong, P., Liao, X., Chen, Z., et al. An improved method for predicting $\mathrm{CO}_{2}$ minimum miscibility pressure based on artificial neural network. Adv. Geo-Energy Res. 2019, 3(4): 355-364.

Li, P., Hao, M., Hu, J., et al. A new production decline model for horizontal wells in low-permeability reservoirs. J. Pet. Sci. Eng. 2018, 171: 340-352.

Liu, S., Zhang, L., Zhang, K., et al. A simplified and efficient method for water flooding production index calculations in low permeable fractured reservoir. J. Energy Resour. Technol. 2019, 141(11): 112905.

Luo, X., Zhao, C., Liu, Y. Study on deliverability evaluation of offshore heavy oil field at initial stage of production. Fault Block Oil and Gas Field 2011, 18(5): 630-633. (in Chinese)

Qian, W., Yin, T., Hou, G. A new method for clastic reservoir prediction based on numerical simulation of diagenesis: 
A case study of the Ed1 clastic sandstones in the Bozhong depression, Bohai Bay Basin, China. Adv. Geo-Energy Res. 2019, 3(1): 82-93.

Rinaldi, Harris, H.D. Prediction of specific productivity index for sihapas formation in uncored wells of minas field using limited available core and log data. Paper SPE 38037 Presented at the SPE Asia Pacific Oil and Gas Conference, Kuala Lumpur, Malaysia, 14-16 April, 1997.

Stalgorova, E.L. Practical analytical model to simulate production of horizontal wells with branch fractures. Paper SPE 162515 Presented at the SPE Canadian Unconventional Resources Conference, Calgary, Canada, 30 October-1 November, 2012.

Stalgorova, K., Mattar, L. Analytical model for unconventional multifractured composite systems. SPE Reserv. Eval. Eng. 2013, 16(3): 246-256.

Suykens., J.A.K., Vandewalle, J. Least squares support vector machines. Int. J. Circuit Theory Appl. 2002, 27(6): 605615.

Tang, E., Han, G., Zhang, X., et al. The impact of unbalanced reservoir pressure on lateral well deliverability. Special Oil and Gas Reservoirs 2009, 16(4): 60-62. (in Chinese)

Torcuk, M.A., Kurtoglu, B., Fakcharoenphol, P., et al. Theory and application of pressure and rate transient analysis in unconventional reservoirs. Paper SPE 166147 Presented at the SPE Annual Technical Conference and Exhibition, New Orleans, USA, 30 September-2 October, 2013.

Wang, J., Xu, J., Wang, Y., et al. Productivity of hydraulicallyfractured horizontal wells in tight oil reservoirs using a linear composite method. J. Pet. Sci. Eng. 2018, 164: 450-458.

Wang, W., Shahvali, M., Su, Y. A semi-analytical model for production from tight oil reservoirs with hydraulically fractured horizontal wells. Fuel 2015, 158: 612-618.

Wang, W., Su, Y., Sheng, G., et al. A mathematical model considering complex fractures and fractal flow for pressure transient analysis of fractured horizontal wells in unconventional oil reservoirs. J. Nat. Gas Sci. Eng. 2015, 23: 139-147.

Wang, Z., Sun, B., Sun, X. Calculation of temperature in fracture for carbon dioxide fracturing. SPE J. 2016, 21(5): 1491-1500.
Wei, G., Liu, J., Sun, J., et al. Study on nonlinear multifunctional sensor signal reconstruction method based on LS-SVM. Acta Automatica Sinica 2008, 34(8): 869-875. (in Chinese)

Xie, X., Zhou, B., Wen, F. A research method of production capacity for new oil field. Petroleum Exploration and Development 1997, 24(4): 57-60. (in Chinese)

Xu, Y., Ren, Y., Ding, L., et al. Prediction of profile control result using support vector machihes. Fault Block Oil and Gas Field 2007, 14(2): 50-52. (in Chinese)

Yuan, B., Moghanloo, G.R. Analytical modeling improved well performance by nanofluid pre-flush. Fuel 2017, 202: 380-394.

Yuan, B., Moghanloo, G.R., Zheng, D. A novel integrated production analysis workflow for evaluation, optimization and predication in shale plays. Int. J. Coal Geol. 2017, 180: $18-28$.

Zhang, F., Xu, N., Yu, T., et al. Impact of vertical heterogeneity on well productivity in multilayered low-permeable reservoir. Special Oil and Gas Reservoirs 2002, 9(4): 39-42. (in Chinese)

Zhang, L., Tian, J., Zhu, G. Evaluation methods for initial productivity of directional wells in offshore fault block oilfields. Petroleum Drilling Techniques 2015, 43(1): 111-116. (in Chinese)

Zhang, L., Zhang, J., Li, Y., et al. The research and application of new horizontal well productivity formula based on pseudo steady state time. Science Technology and Engineering 2014, 14(32): 38-42. (in Chinese)

Zhong, Y., Zhang, Z., Zhu, H. A new method to predict production of oilfields in ultrahigh water-cut stage. Fault Block Oil ang Gas Field 2011, 18(5): 641-644. (in Chinese)

Zhou, K., Yang, C., Mu, X., et al. Intelligent prediction algorithm for floatation key parameters based on image features extraction. Control and Decision 2009, 24(9): 1300-1305.

Zhu, S., Li, H., Sun, Z., et al. Unsteady productivity model of mult-stage fractured horizontal well in low permeability gas reservoir. Journal of Shenzhen University Science and Engineering 2014, 31(03): 266-272. (in Chinese) 